\title{
COMPARATIVE STUDY OF VARIOUS METHODS FOR COMPUTATION OF ENERGY DISSIPATION OVER STEPPED SPILLWAY
}

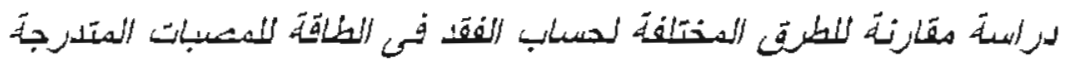

M.I.ATTIA (1) \& M.A.EL-GAMAL (2)

(1) Asst. Prof. Water \& Water Structures Engineering Dept Faculty of Engineering, Zagazig University, Egypt

(2) Assoc. Prof. Irrigation \& Hydraulic Engineering Dept Facuity of Engineering, Mansoura University, Egypt

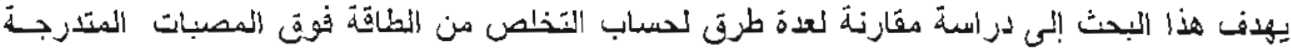

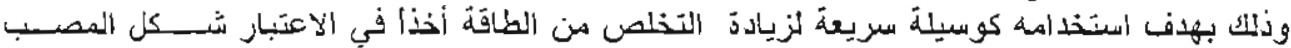

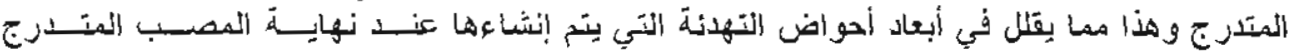

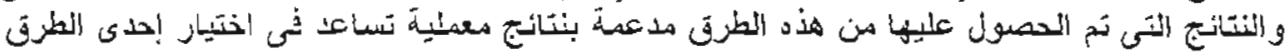

\section{ABSTRACT}

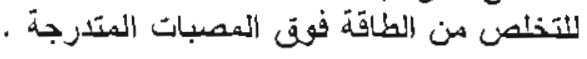

Stepped spillways have become popular with the method of construction adopted for roller Compacted concrete dams. The steps provided on the surface of open spillways help to increase the rate of energy dissipation taking place on the spillway face to reduce the size of stilling basin generally provided at the toe of spillway. The regine of flow over stepped spillway can be either skimming or nappe type. This paper describes the various methods available for computation of energy dissipation over stepped spillway for both the regimes. The results obtained by these inethods axe compared with the available experimental data, which would heip in selecting more accurate inethod for computation of energy dissipation.

\section{INTRODUCTION}

In case of stepped spillway, the spillway face is provided with series of steps from near the crest to the toe. In the ogee shaped portion of the spillway, the steps provided are of varying sizes. This portion of the stepped spillway is called as the transition region steps of the same size which are provided on the uniform slope of spillway (Fig . I a). These steps provide additional resistance the flow, which results in considerable dissipation of energy over the surface of spillway. In general, the flow over scepped spillway can be classified into two regimes depending on its characteristics. These two regimes are (I) skimming flow (II) nappe flow (Fig, $1 \mathrm{c}$ and I d). In the skimming flow regime, water flows in the form of a regular stream over the steps and flow is supercritical 
throughout and most of energy is dissipated to maintain stable horizontal vortices formed beneath the regular stream and between the external edges of the steps. Where as, in the nappe flow regime, water stream from a series of plunges on each step and flow is subcritical over each step or over a part each step and dissipation of energy occurs due to jet break up in the air, jet mixing on the step, formation of fully developed or partial hydraulic jump on the step. The different methods for estimation of energy dissipation for skimming flow regime lave been suggested by various investigators like Rajaratnam (1990), Stephanson ( 1991), Bayat ( 1991 ) and Tozzi (1994). Whereas, for nappe flow regime, the available methods in literature are by Chamani and Rajaratnam (1994). These methods are based on certain assumptions and approximations and hence, it is necessary to compare the results with available experimental data so as to select the most accurate method for computation of energy dissipation which is needed in practice for designing of stilling basin. This paper describes the various methods available for computation of energy dissipation in both, skimming and nappe flow regimes over stepped spillway and compares the result obtained by these methods using available experiment data .

\section{ENERGY DISSIPATION OVER STEPPED SPILLWAY}

The energy loss over stepped spillway is expressed as:

$$
\triangle E=E-E t
$$

The relative energy loss is expressed as :

$$
\triangle E / E=(E-E t) / E
$$

In which:

$$
\begin{aligned}
& E=H+1.5 y=\text { Energy at the crest of spillway, } \\
& E t=y+V / 2 g=\text { Energy at the toe of spillway, } \\
& H=\text { Height of spillway, } \\
& y=\text { Critical depth of flow, } \\
& y=\text { Flow depth at the toe of spillway, and } \\
& V=\text { Toe velocity. }
\end{aligned}
$$

By knowing either the value of $y$ and $V$, the energy loss $\Delta E$ can be calculated using equation (1) for the known values of discharges and height of dam. Hence, most of the methods of computation of energy loss are based on the computation of toe velocity or toe depth. 


\section{METHODS FOR COMPUTATION OF ENERGY DISSIPATION FOR SKIMMING FLOW REGIME OVER STEPPED SPILLWAYS}

(1) Rajaratnam method: Rajaratnam (1990) presented a method for estimation of energy loss for skimıning flow over stepped spillway by assuming that the uniform flow conditions are reached before the end of spillway and uniform flow equations for open channel are used for the computation of uniform velocity at the toe of spillway. the resulting equations are:

$$
\begin{aligned}
& \mathrm{V}=(2 / \mathrm{Cf}) \quad(\mathrm{gyS}) \\
& y=\left(\mathrm{Cfq}^{2} / 2 \mathrm{gS}\right)^{1 / 3}
\end{aligned}
$$

Where,

$\mathrm{Cf}=$ Coefficient of fluid friction,

$q=$ discharge per unit width of spillway, and

$S=\sin \theta=$ slope of downstream face of spillway.

The resistance due to steps is expressed in terms of coefficient of fluid friction $\mathrm{Cf}$ and obtained its average value equal to 0.18 which was based on the experimental results of Sorensen (1985). Therefore, it cannot be used with accuracy for different ranges of discharge as well as for different values of downstrean slope of spillways and step heights.

(2)Stephenson Method: Stephenson ( 1991 ) assumed that the flow over stepped spillway is uniform and calculated the uniform flow depth using the Darcy's equation :

$$
S=(f / 4 y) V^{2} / 2 g
$$

Where: $V=q / y^{1 / 3}$

Hence: $y=\left(q^{2} f / 8 g S\right)$

Where: $f=$ Darcy's friction coefficient

Stephenson obtained the value off, using the turbulent rough boundary layer equation:

$$
\begin{aligned}
& \mathrm{f}=1 /[1.14+2 \log 4 \mathrm{y} / \mathrm{k}]^{2} \\
& \mathrm{f}=1 /\left[1.14+2 \log \left(\mathrm{y}_{\tau} / \mathrm{k}\right)^{1 / 3}\right]^{2}
\end{aligned}
$$

Where,

$$
y_{c}=\left(q^{2} / g\right)^{1 / 3} \doteq \text { critical depth of flow }
$$


The roughness height $(\mathrm{k})$ is assumed equal to step height (h)

(3) Bayat Method : Bayat (1991) obtained the flow properties over stepped spillway by using Bater method (chow 1959 ) According to this method for a given roughness height $(k)$ and at a distance $(x)$ from the origin of conventional spillway, mean velocity of flow (V) and normal depth ( $y$ ) in tenns of turbulent boundary layer thickness ( $\delta$ ) may be computed by

$$
\begin{aligned}
& \delta / x=0.024 /(\mathrm{x} / \mathrm{k})^{0.13} \\
& \mathrm{~V}=\left(2 \mathrm{~g} \sin \theta^{0,5}\right. \\
& \mathrm{y}=(0.1 \delta+\mathrm{q} / \mathrm{v}) \cos \theta
\end{aligned}
$$

Bayat assumed that flow that flow over spillway becomes uniform beyond the point of interception of turbulent boundary layer with free surface and this flow depth can be assumed as uniform depth at the toe of spillway.

(4) Tozzi Method: Tozzi (1994) assumed that the flow over stepped spillway is gradually varied and suggested the use of standard step method for computation of toe depth and velocity. The flow resistance due to steps is expressed in terms of Darcy's fiction factor $f$. Based on experimental study of air flow through rectangular duct with comugated boundary surface, Tozzi established general law of friction factor $f$ as:

$$
1 / \mathrm{f}=2.16+1.24 \log (\mathrm{y} / \mathrm{k})
$$

Equation ( 12 ) is suggested for the conventional slope of spillway. $1 \mathrm{~V}: 0.75 \mathrm{H}$.

(5) Writers Method: The flow over stepped downstream face of spillway can be as a uniform flow over a rough boundary. Writers described this type of flow by Manning's equation as

$$
V=1 / n R^{2 / 3} S^{1 / 2}
$$

Where, $V=q / y$
Therefore, $\quad y=\left(q n / S^{1 / 2}\right)^{0.6}$

Where, $n=$ Manning's roughness coefficient;

$\mathrm{R}=$ Hydraulic radius which is equal to $\mathrm{y}$ for wide rectangular channel

Knight \& Mc Donald(1979)analyzed" quasi smooth flow"(skimming flow)over large roughness elements of rectangular cross section and recommended an improved form of bed resistance equation for this type of flow as:

$$
V=U_{*}[0.25+19.0 \log (\lambda / b)+5.75 \log (y / k)]
$$


Where, $U_{*}=(\text { gRS })^{U .3}=$ Shear velocity

Refering to Fig. 1 , values of $\lambda, \mathrm{k}$ and $\mathrm{b}$ can be obtained for a given size and geometry of steps. For a wide rectangular channel, equating the values of velocity given by equation (13) and (15) and using equation (14), the resulting equation can be written as

$$
\mathrm{Zu} 0.1 / \mathrm{n} \cdot \mathrm{g}_{0.5}^{0.5}=0.25+19.0(\lambda / \mathrm{b})+5.75 \log (\mathrm{Zu} 0.6 / \mathrm{k})
$$

Where, $Z_{u l}=\mathrm{nq} / S=$ section factor for computation of uniform flow.

For a given discharge, downstream slope of spillway and step size, the values of Manning's coefficient of roughness ( $\mathrm{n}$ ) can be detennined from equation (16) with the value of the toe depth and toe velocity can be computed from equation (14) and (13).

(6) Chanson Method: Chanson ( 1994 ) assumed that the uniform flow conditions are reached before the end of spillway, the depth of flow and flow velocity are deduced from the momentum equation and the energy loss equation for ungated spillway is given as :

$$
\triangle E / E=l-\left\{(\mathrm{f} / 8 \sin \theta)^{1 / 3} \cos \theta+0.5(\mathrm{f} / 8 \sin \theta)\right\} /\left(2 / 3+\mathrm{H} / \mathrm{y}_{\mathrm{c}}\right)
$$

Chanson analyzed experimental data from various sources for skimming flow regime and shown that the friction factor $f$ varied between 0.5 and 4 with mean value of about 1.3 and hence, recommended value of $f$ as 1.3 for stepped spillway.

\section{METHODS FOR COMPUTATION OF ENERGY DISSIPATION FOR NAPPE FLOW REGIME}

(1) Chamani and Rajartham Method: Chamani and Rajaratham (1994) Presented a method for estimating the energy loss on horizontal stepped spillway for nappe flow regime, by introducing the concept of $\propto$, which has been defined as the proportion of energy loss on each step. They derived the expression for energy loss as:

$$
\triangle E / E=1-\left\{(1-\infty)^{N}\left[1+1.2\left(y_{c} / h\right)\right]+\Sigma(1-\infty)^{i} / N+1.5\left(y_{c} / h\right)\right\}
$$

Where, $\mathrm{N}=$ Number of steps .

The proportion of energy loss per step $\propto$ is not a constant but varies with slope of spillway ( $\sin \theta=\tan \theta=h / 1$ ). Using the experimental results of Horner (1978), the variation of $\propto$ with h/l was described as: 


$$
\alpha=a-b \log \left(y_{c} / h\right)
$$

Wherein the coefficient $a$ and $b$ are described by the following equation.

$$
\begin{aligned}
& a=0.3-0.35(\mathrm{~h} / \mathrm{l}) \\
& b=0.54+0.27(\mathrm{~h} / \mathrm{p})
\end{aligned}
$$

(2) Writers Method : Using Rands ( 1955 ) expression for the depth (y) at the toe of the nappe of a straight drop spillway for nappe flow regime is expressed as :

$$
\begin{aligned}
& \triangle E / E=1-\left\{\left[(y / h)+0.5 D(h / y)^{2}\right] / n+1.5\left(y_{c} / h\right)\right\} \\
& \text { Where, } y / h=0.54 D^{0.425}
\end{aligned}
$$

$$
\text { And } \quad \mathrm{D}=\mathrm{q}^{2} / \mathrm{gh}^{3}=\text { Drop number }
$$

\section{COMPARISON WITH EXPERIMENTAL OBSERVATIONS}

\section{(1) SKIMMING FLOW REGIME}

In order to compare the accuracy of the methods described in this paper, experimental data published by Sorensen (1985), Bayat (1991), Tozzi (1994) and Christodouliul (1993) is considered. Variation of energy dissipation $\mathrm{H} / \mathrm{y}$ for Sorensen experimental data is shown in Fig. 2, for Bayat experimental data is shown in Fig. 3. for Christodoullil experimental data is shown in Fig. 3 and for Tozzi experimental data is shown in Fig. 5. It can be seen from Fig.2, and Fig. 3 that the method suggested by Chanson, Writers and Stephenson compares better with Sorensen and Bayat experimental observations. The energy dissipation computed by the methods suggested by Stephenson, Bayat and Writers varies considerably from Christodoulin experimental observations and hence, its variation With $\mathrm{H} / \mathrm{y}$ for Christodouliu experimental data is not shown in Fig. * This is because of the face that Clristodoulin obtained his observation on a model of lower height ( about $0.3 \mathrm{~m}$ ) and therefore the flow in his model was gradually varied. Tozzi's method considers gradually varied flow over stepped spillway and hence, gives better agreement with Christodouliu observations (Ref. Fig.4). Fig.j shows that the methods suggested by Writers, Steplenson and Tozzi compares better with Tozzi experimental data . 


\section{(2) NAPPE FLOW REGIME}

The energy dissipation $\Delta E / E$ ) calculated by the methods suggested by Chamani and Rajartnom and Writers for Essay and Horner's experimental data is compared with experimental observations as Shown in Fig.6. Compared to experimental observations, the average error in prediction from the method suggested by Chamani is $0.85 \%$, while in case of the method suggested by Writers, it is $2.89 \%$. Since the prediction from the Writer's method is based on Rand's (1955) expressions, which are derived from Rand's experimental data, it can not be as accurate as prediction from Chamani and Rajartnam which is based on regression analysis of Essery and Horner's data, when compared to their experimental data - However, Writer's method can be considered inore general and comparatively convenient for application.

\section{CONCLUSION}

The accurate estimation of energy dissipation over stepped spillway is essential for design of stepped spillway and its energy dissipation arrangement. In this paper, various methods for computation of energy dissipation are described for both the skimming flow and nappe flow. The values of energy dissipation computed by these methods for different experimental data are compared with observed values. For skimming flow regime, where the height of spillway is the method suggested by the Writers can be considered to be a better one as it gives the least total average error and the least total standard deviation with observed values of various experimental data For the moderate height or smaller of spillway, where the flow is gradually varied. The method suggested by Tozzi can be recommended.

For nappe flow regime, method suggested by Chamati and Rajartnam gives better agreement with the observcd values. It also, considers the effect of downstream slope of spillway on energy dissipation. However, the method suggested by the Writers although it is more general but still convenient for application .

\section{REFERENCES}

(1) Bayat, H.O. (1991) "Stepped spillway feasibulity investigation" "XVI ICOLD Congress VoI. III. Q66. R98, Vienna, Austria, pp. 1803 - 1817.

(2) Chow, V.T. (1959), "Open Channel Hydraulics" Mc Graw - Hill Pulc.

(3) Christodoulou, G.C. (1993) "Energy dissipation on stepped spillways" J.Hydraulic Engineering, ASCE, Vol . 120, (2) , pp. 254.-259. 
(4) Chamani, M.R and Rajaratnam, N. (1994), "Jet flow on stepped spillways" J.Hyd. Engg. ASCE, vol. 119, (5), pp. 644-650.

(5) Chanson. H. (1994), "Comparison of energy dissipation between nappe and skimming flow regimes on stepped chues" J. Hydraulic research, Vol. 32 , pp. $213-218$.

(6) Essery, I. T. S. and Horner, M. W (1978) "The Hydraulic design of stepped spillways" CIRIA Report NO.33, Jan., London, U.K.

(7) Rajartnam, N. (1990). "Skimming flow in stepped spillway " J. Hydraulic Engg. ASCE, VOL. 116, (4), pp. 587-59l.

(8) Sorensen, R.M (1985), "Stepped spillway hydraulic model investigation" J. Hydraulic Engg. ASCE, VOL-ПI (12), PP. 1416 - 1472 .

(9) Stephenson, D. ( 1991 ) "Energy dissipation down stepped spillways" Water Power and Dam Constr. , U.K., (9) , PP .27-30

(10) Tozzi, M.J. (1994)" Residual energy in stepped spullways" Water power and Dam Constr. U.K., (5) PP. 32-34

(11) Tatewar , S.P. and Ingle, R.N. (1995) "Discussion of Jet flow on stepped spillways "J. Hydraulic Engg, ASCE, Vol, 121, (5), PP. 445446.

(12) Tatewar, S.P. and Ingle, R.N. (1996), "Resistance to Skimming flow over stepped spllways "Int. Sem. on civil Engg. Practice in twenty first Century, Roorkee, India . 


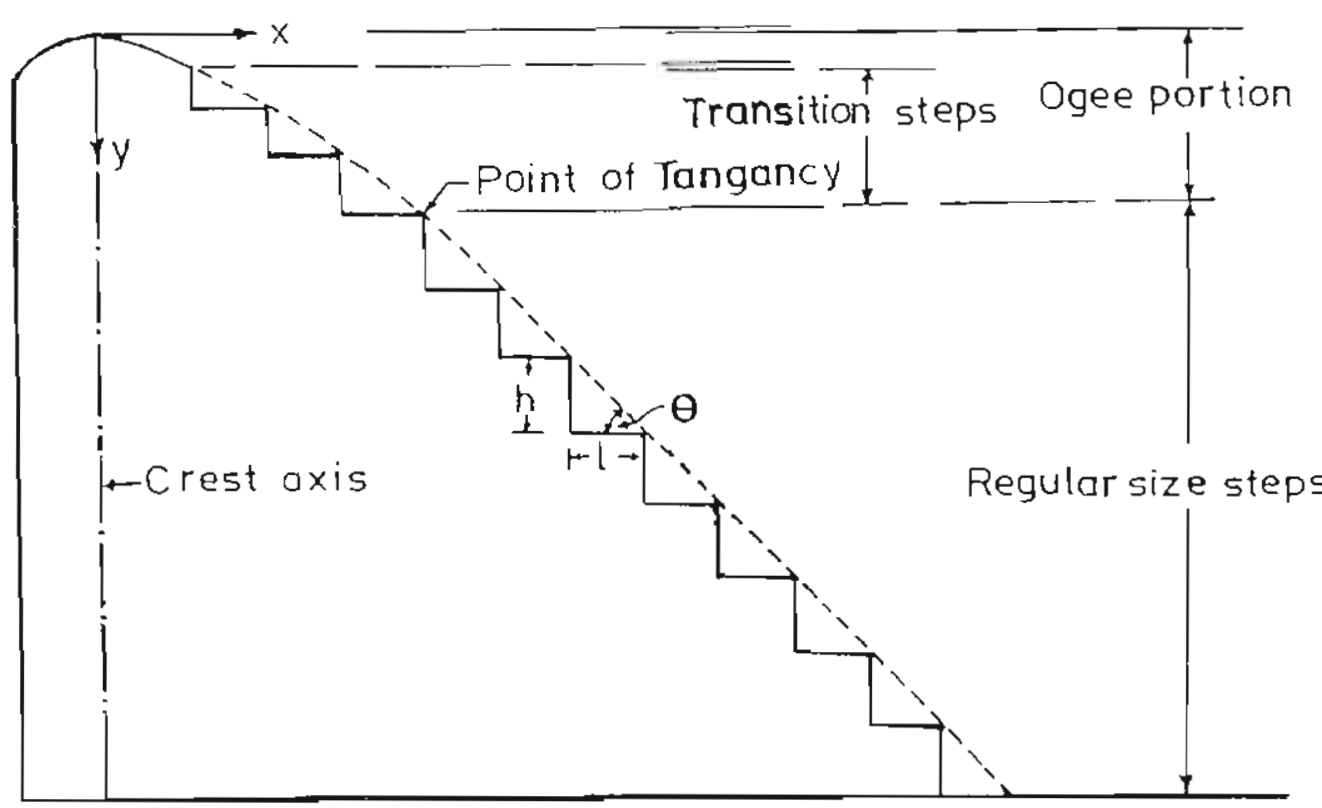

(a)
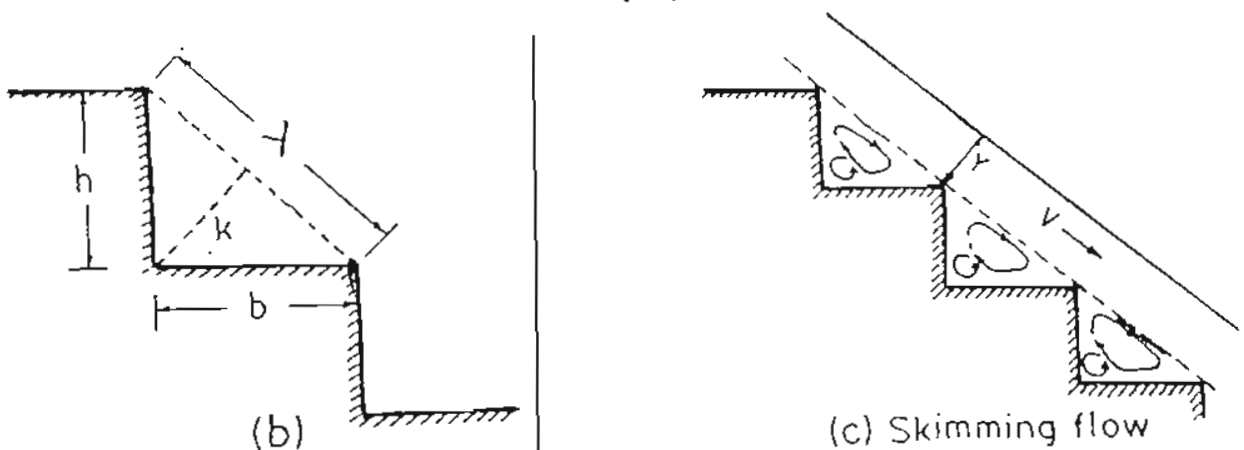

(b)

(c) Skimming flow

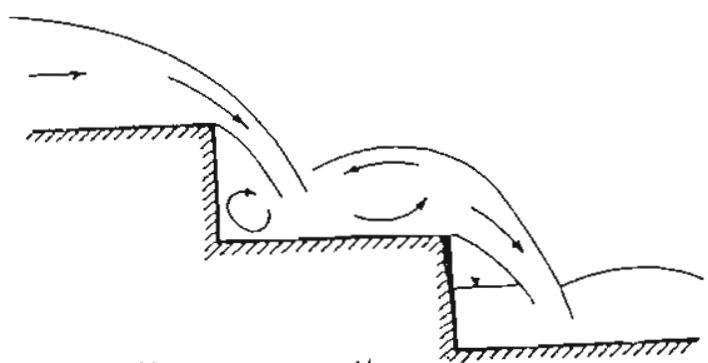

(d) Nappe flow

Fig. 1 Definition sketch for stepped spillway 

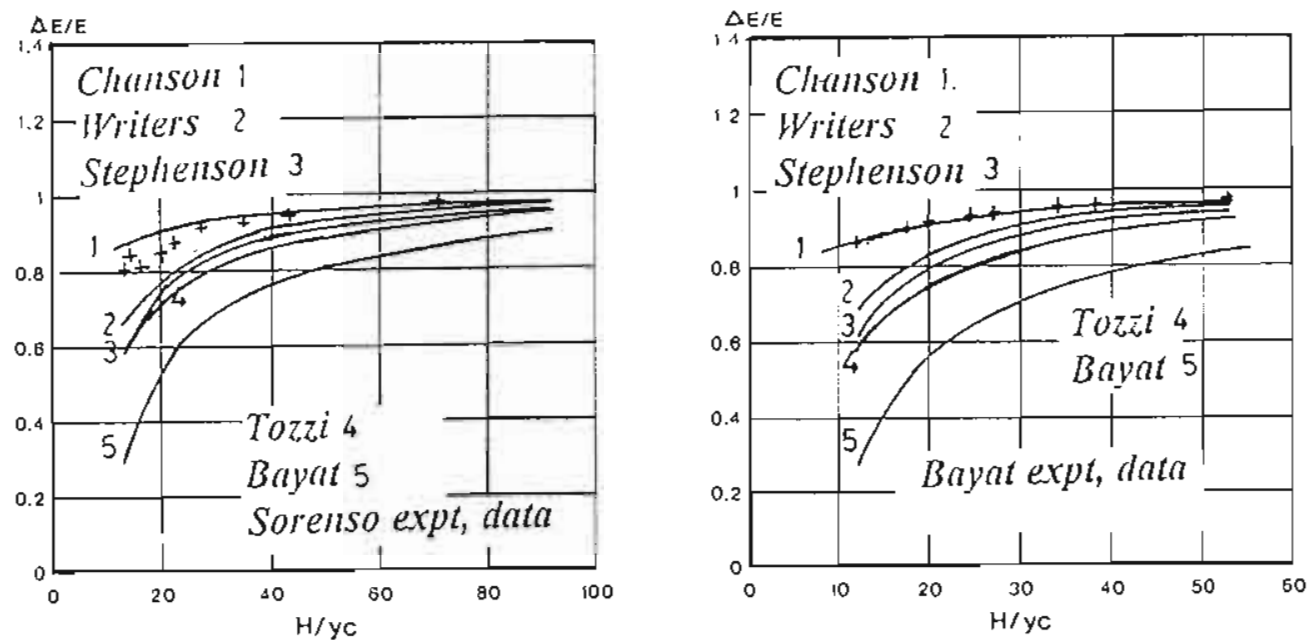

Fig, 2 Variation of $\triangle \mathrm{E} / \mathrm{E}$ With $\mathrm{H} / \mathrm{y}_{\mathrm{C}}$

Fig .3 Variation of $\triangle \mathrm{E} / \mathrm{E}$ with $\mathrm{H} / \mathrm{y}_{\mathrm{C}}$
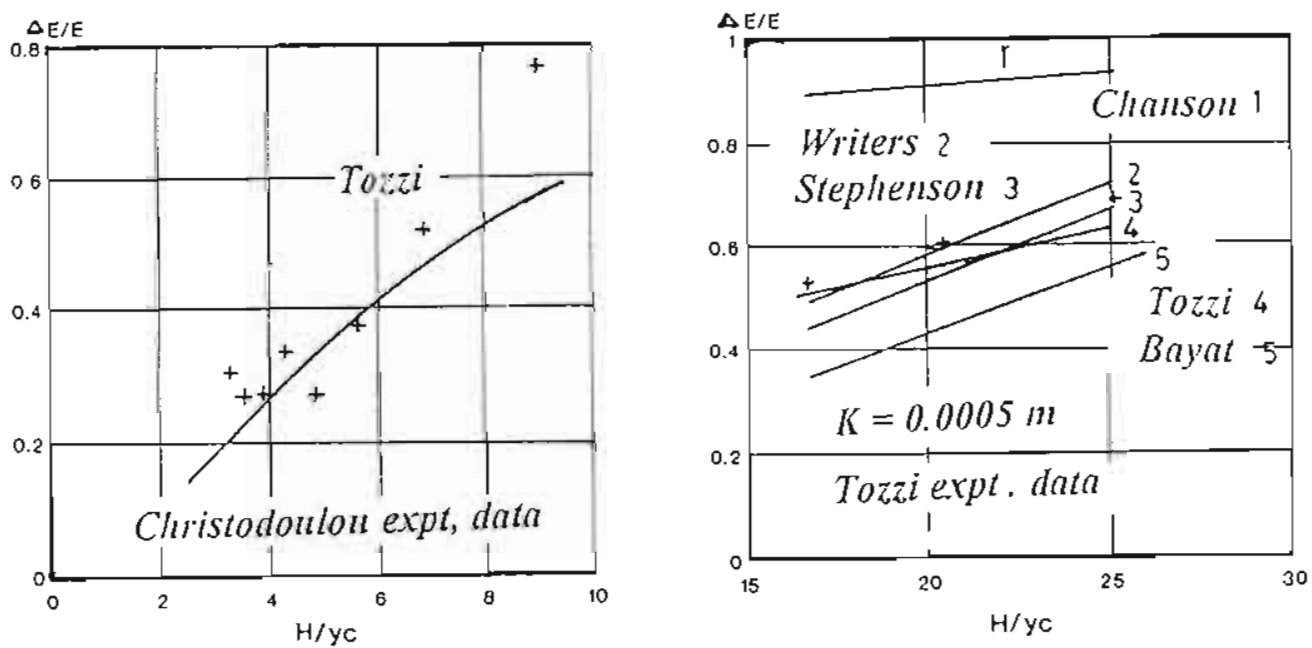

Fig .4 Variation of $\Delta \mathrm{E} / \mathrm{C}$ With $\mathrm{H} / \mathrm{y}_{\mathrm{c}}$

Tig .5 Variation of $\triangle \mathrm{E} / \mathrm{E}$ with $\mathrm{H} / \mathrm{y}_{\mathrm{c}}$ 


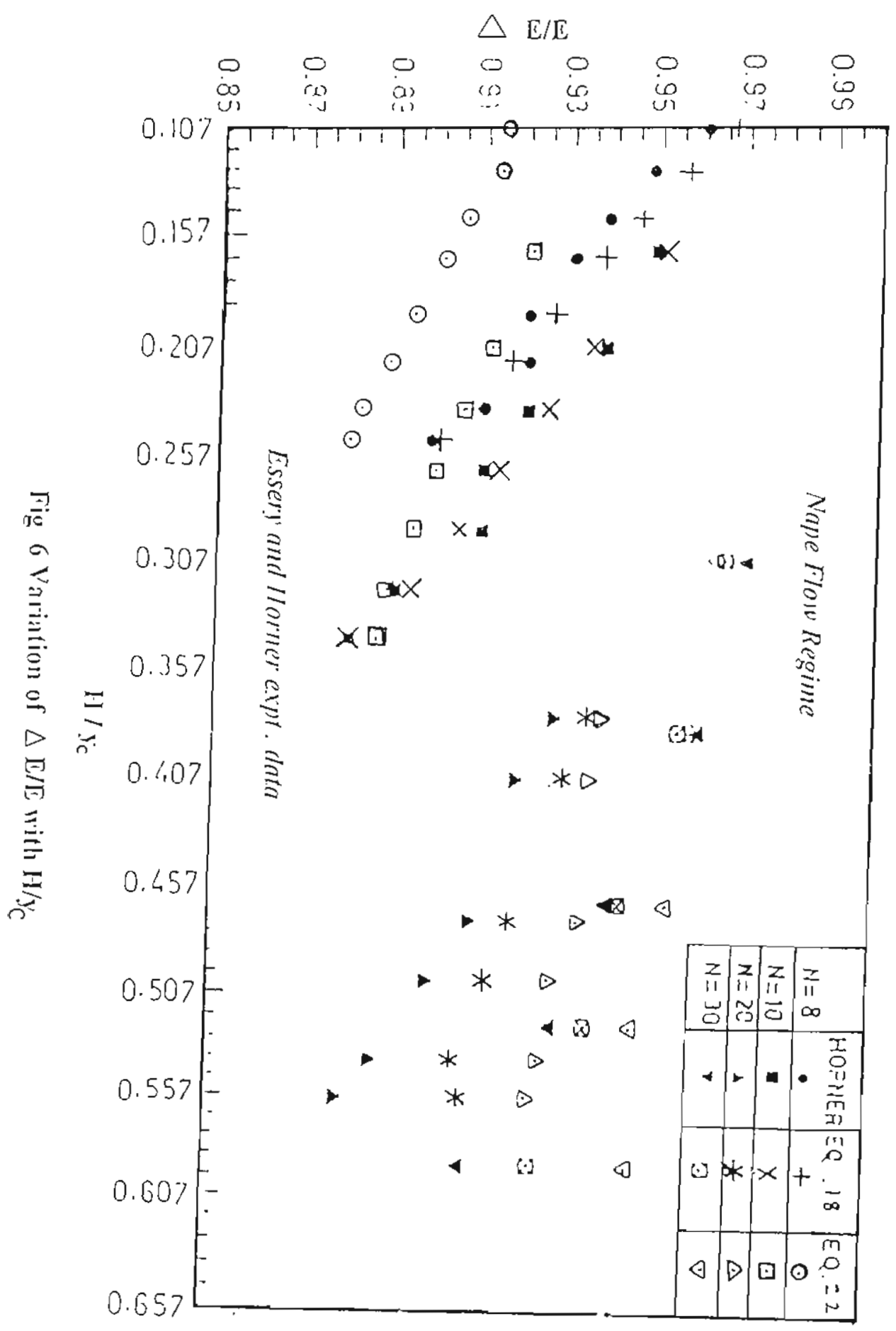

